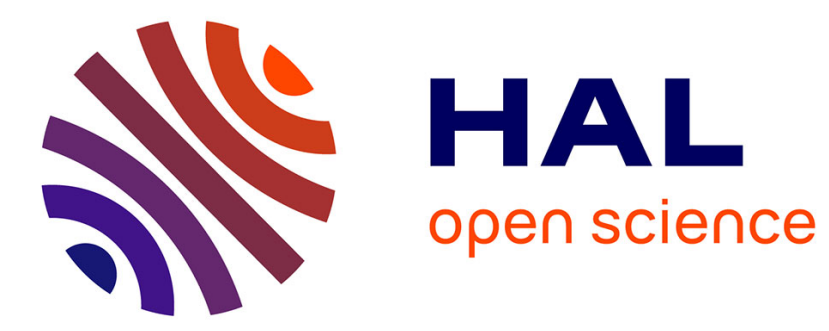

\title{
Support optimization for additive manufacturing: application to FDM
}

Nicolas Boyard, Olivier Christmann, Mickael Rivette, Olivier Kerbrat, Simon Richir

\section{- To cite this version:}

Nicolas Boyard, Olivier Christmann, Mickael Rivette, Olivier Kerbrat, Simon Richir. Support optimization for additive manufacturing: application to FDM. Rapid Prototyping Journal, 2018. hal01921629

\section{HAL Id: hal-01921629 \\ https://hal.science/hal-01921629}

Submitted on 22 Nov 2018

HAL is a multi-disciplinary open access archive for the deposit and dissemination of scientific research documents, whether they are published or not. The documents may come from teaching and research institutions in France or abroad, or from public or private research centers.
L'archive ouverte pluridisciplinaire HAL, est destinée au dépôt et à la diffusion de documents scientifiques de niveau recherche, publiés ou non, émanant des établissements d'enseignement et de recherche français ou étrangers, des laboratoires publics ou privés. 


\section{Emerald Rapid Prototyping Journal}

\section{Support optimization for additive manufacturing: application to FDM}

\begin{tabular}{|r|l|}
\hline Journal: & Rapid Prototyping Journal \\
\hline Manuscript ID & RPJ-04-2016-0055.R2 \\
\hline Manuscript Type: & Original Article \\
\hline Keywords: & $\begin{array}{l}\text { Additive manufacturing, Support optimization, Methodology, FDM, CAD, } \\
\text { DFAM }\end{array}$ \\
\hline
\end{tabular}

\section{SCHOLARONE" \\ Manuscripts}

Nicolas Boyard, (LAMPA, Arts et Metiers ParisTech - Campus d'Angers, Angers, France)

Olivier Christmann, (LAMPA, Arts et Metiers ParisTech - Campus d'Angers, Angers, France)

Mickaël Rivette, (LCFC, Arts et Metiers ParisTech - Campus de Metz, Metz, France)

Olivier Kerbrat, (Ecole Normale Supérieure de Rennes, Université Bretagne-Loire, Bruz, France)

Simon Richir, (LAMPA, Arts et Metiers ParisTech - Campus d'Angers, Angers, France) 


\section{Support optimization for additive manufacturing: application to FDM}

\section{Abstract \\ Purpose}

This paper aims to present a new methodology to optimize the support generation within the FDM process.

Design/methodology/approach

Different methods of support generation exist, but they are limited with regards to complex parts. This paper proposes a method dedicated to support generation, integrated into CAD software. The objective is to minimize the volume of support and its impact on a part's surface finish. Two case studies illustrate the methodology. The support generation is based on an octree's discretization of the part.

\section{Findings}

The method represents a first solid step in the support optimization for a reasonable calculation time. It has the advantage of being virtually automatic. The only tasks to be performed by the designer are to place the part to be studied with respect to the CAD reference and to give the ratio between the desired support volume and the maximum volume of support.

\section{Research limitations/implications}

In the case studies, a low gain in manufacturing time was observed. This is explained by the honeycomb structure of the support generated by a common slicing software whilst the proposed method uses a "full" structure. It would be interesting to study the feasibility of an optimized support, with a honeycomb structure but with a preservation of the surface which is in contact with the part.

\section{Originality/value}

This solution best fits the needs of the designer and manufacturer already taking advantage of existing solutions. It is adaptable to any part if the withdrawal of support is taken into account. It also allows the designer to validate the generation of support throughout the CAD without breaking the digital chain.

\section{Introduction}




\subsection{Support in the additive manufacturing process}

Additive manufacturing (AM) brings new characteristics as compared to conventional manufacturing processes: the realization of complex shapes, multi-material parts and mobile assemblies (parts printed together with internal mobilities). But the design is subject to new constraints, including the need for support during the manufacturing of certain parts (Dolenc and Makela, 1994; Gibson et al., 2010) and the choice of the orientation of the part to be printed (Ponche et al. 20). More specifically, in the Fused Deposition Modeling (FDM) process (Pham and Gault, 1998), the support structure is often voluntarily brittle or soluble (Nowotny et al., 2007) in order to remove it from the part after manufacturing. Since support is deposed with the part, less support decreases manufacturing time and cost (Singh, 2013; Durgun and Rukiye, 2014). Although we specifically work on FDM processes, support optimization is also studied for SLM (Calignano, 2014).

During the printing, the junction between the material layers revealed defects that degrade the part's surface finish as well as its mechanical properties (Mognol et al., 2006). These defects, known as the "staircase effect", are due to the discretization of the surface in parallel layers of constant thickness (Ma et al., 2004). Since the layers are always filed under the same plan, it is easy to predict the defects that will appear on the part, as this latter generally has an orthotropic behavior. A proper part orientation may limit the impact of these defects (Ahn et al., 2002). In addition, the presence of the support, as well as the mechanical properties and the surface finish, depend only on the orientation of the part (Figure 1) (Canellidis et al., 2009). The part's orientation makes it possible to limit the amount of support, with a direct impact on the manufacturing time (related to the amount of material), the duration of the support removal and the eventual surface finishing. However, it is not always possible to completely remove the support, for example in the case of difficulties to reach closed areas.

Currently, the placement of the support is automatically taken into account by the slicing software without optimization of the volume or the surface finish, both of which increase manufacturing and "cleaning" time. To address these two issues, the support must be integrated when creating the part's digital mock-up. This constraint raises two questions. First, is it necessary to optimize the placement of the support to limit surface defects and thus to reduce material consumption and manufacturing costs? Secondly, once the placement of the support is optimized, must its extraction be taken into account (e.g., closed cavities must be avoided). 
Areas with support must be easily accessible to limit the removal time, whether manual or automated, using a chemical or physical process.

\subsection{Automatic generation of support}

Different methods of support generation exist, but they are limited with regards to complex parts (Allen S. and Dutta D., 1995; Swaelens B.et al., 1995). As this generation is performed on the stl model, it is difficult to optimize directly the native model. In both cases, the support generation is often oversimplified: where a layer is not supported by any material, a block of material is generated regardless of the consequences of its presence.

Some softwares are dedicated to optimizing the support. The MeshMixer software analyzes the placement of the support in real time using simple parameters such as the minimum support angle and density of the support. This angle corresponds to the inclination that can be accepted by the material, during the deposition above the void. Beyond this angle, it is necessary to provide support to avoid collapse. Using the minimum angle support helps generate a very small volume of support material. However, the shape of the support generated by MeshMixer does not cover the entire surface of the part, which then leads to local collapses during printing. The carrier is also generated perpendicular to the printing direction: the contact between the support and the part is partial, which creates shape ruptures (Figure 2). Finally, it happens that the support intersects the workpiece.

Another slicing software offers different geometries (Strano et al., 2012), but these geometries are based on a pattern that is repeated in translation in the $\mathrm{X}, \mathrm{Y}$ and $\mathrm{Z}$ axes of the part. This kind of support allows the reduction of the amount of material used, but is not really suited to the geometry of the part and overlooks the surface finish.

The lack of relevant solutions for the support integration in the case of complex parts leads one to conclude that it is necessary to perform this step during the part design stage. This will better reflect the surface finish, the manufacturability of the part and the withdrawal of the support.

\subsection{Specificities of the support regarding FDM process}

The optimization of the support requires the consideration of the following constraints:

- The support geometry must be adapted to the final part geometry; 
- The geometry must be validated before the slicing operation to allow modifications to the CAD model;

- All areas with support must be accessible for support removal.

The FDM process has two interesting characteristics. Firstly, it is possible to manufacture a form "in cantilever" if the minimum support angle $\alpha$ is respected. Secondly, making support in a soluble material, such as PVA or PLA, facilitating its removal without accessibility constraints. By generating a geometry incorporating a support with the minimum slope angle $\alpha$, it is also possible to reduce the amount of material and therefore the manufacturing time.

A tree geometry will continuously cover the entire surface to support while eliminating defects of MeshMixer software. However, it is not possible to erase the staircase effect. Therefore, the method is based on a generic shape which (Figure 3) consists of a vertical column surmounted by an inverted pyramid. This geometry will be named "column".

\section{Method of support optimization}

\subsection{Generalities}

In order to integrate the support optimization in the design stage, a new method dedicated to support generation (Figure 4) is proposed. It is based on an integrated tool in a CAD software. The aim of this method is to optimize the volume of support and its impact on the surface finish. In this method, steps from the discretization of the CAD model to modeling of the support do not have a physical representation in the digital mockup. These steps correspond to an analysis phase for the generation of the optimized support for a given part. The analysis of the part may be made independently or integrated within a CAD software. This method is illustrated by two case studies (Figure 5): a brace and a flange. The first case study (the flange) will be detailed step by step according to our method. For the second example (the brace), we will only present key steps and the result of our optimization. These two case studies have geometries for which our method may have a significant interest in the context of a gain of time and material. SolidWorks is the CAD software and Microsoft Excel is used to perform all calculations. These choices were made to enable software interoperability and to assess whether or not the support optimization method can be implemented using simple tools.

The remaining sections will explain the different steps of the proposed method. 


\subsection{CAD model of the part}

By convention, the part must be positioned in the positive quadrant of three-dimensional system of the CAD software. The $x-y$ plane corresponds to the representation of movable table of the AM machine. The z-axis corresponds to the manufacturing direction. This positioning is used for the analysis of the part and the automatic support generation.

\section{Application to the case study}

The bounding volume of the part corresponds to a cube of $30 \mathrm{~mm}$ side. This volume is a restricted area of the case study part which requires support. The part is oriented with respect to the AM machine space, it remains only to position it within the space of the CAD software (Figure 6).

\subsection{Discretization of the CAD model}

The CAD model is then discretized with an octree decomposition, using the method defined by (Kerbrat et al., 2010). An octree decomposition will represent a part by the division of space into three types of voxels, named octants: black octants are those that are completely contained within the part, whereas white ones are those that are completely outside, and gray ones are partially outside and partially inside the part (Figure 7). The main advantage is that the discretization can acquire relatively high accuracy, and that the geometry obtained with the octants will be very close to the part geometry.

The starting point for the octree decomposition is the smallest cube V0 encompassing the part. Regarding the positioning of the part, three $\mathrm{V} 0$ faces are merged with the $\mathrm{x}-\mathrm{y}, \mathrm{x}-\mathrm{z}$ and $\mathrm{y}-\mathrm{z}$ planes of the $\mathrm{CAD}$ coordinate system. To physically remove the approximations of the analysis, the decomposition must provide octants whose dimensions are lower or equal to the z precision of the machine. Knowing the coordinates of the vertices of each octant, it is quite simple to generate a support respecting an angle $\alpha$ of $45^{\circ}$, which is a good approximation of $\alpha$.

The edge $a_{i}$ of an octant with the decomposition level $i$ is equal to ( 0 is the edge of the $V 0$ volume):

$$
a_{i}=\frac{a_{0}}{2^{i}}
$$


To allow a top-down analysis from $V 0$ to the smallest necessary octant, each intermediate octant must be saved. The maximum number of octants to be stored is given by the following relationship:

$$
n=\sum_{i=1}^{9} 8^{i}
$$

\section{Case study}

The diameter material strand deposited by the nozzle is $0.25 \mathrm{~mm}$. The part to be analyzed is contained in a $30 \mathrm{~mm}$ edge cube. According to the formula given above, for $a_{0}=30 \mathrm{~mm}$ and $a_{i}<0.25 \mathrm{~mm}, i$ must be lower or equal to 6 , which corresponds to a maximum of 2396744 octants.

\subsection{Representation of the model in a matrix form}

Once the part is divided into octants, they are retrieved from the table using stacks. Each stack contains all the octants with the same $\mathrm{X}$ and $\mathrm{Y}$ coordinates, sorted in ascending $\mathrm{Z}$. For each stack, depending on the presence of a white or a black octant above and / or below a gray octant, two types of surfaces are deducted: the surface to support and the supporting surface used to position columns. The surfaces to support are then recorded into matrixes named Supporting Surface Matrix (SSM) (Figure 8). Each SSM is coupled to a matrix of the same size representing the supporting surface. The supporting surface may be a combination of surfaces from the manufacturing machine table and the part itself.

A SSM is composed of numerical and color data. The numbering of the boxes starts at 1 . Each cell $(i ; j)$ of the matrix contains a numerical value:

- $\quad i$ and $j$ are odd: the height of a mesh point;

- $\quad i$ and $j$ are even: the priority index of the block to support (a block is defined as a white octants stack);

- $\quad i$ is odd and $j$ is even: the angle $\alpha$ between the two points of coordinates $(i ; j-1)$ and $(i ; j+1)$;

- $\quad i$ is even and $j$ is odd: the angle $\alpha$ between the two points of coordinates $(i-1 ; j)$ and $(i+1 ; j)$.

A color code is assigned according to the value of the cell.

The color of a mesh point gives the following indications:

- light green: the point does not belong to any block already supported and cannot be selected as the center of a pillar; 
- dark green: the point is located at the intersection of four blocks to support and can be selected as the center of a pillar;

- $\quad$ red: the point is encompassed by the construction of a pillar;

- dark gray: the point is already supported.

The priority index of a block may take five values: $0,1,10,100$ or 1000 . By default, the priority of a block is set to 1 . A block $(i, j)$ has four physical neighboring blocks $(i+2, j),(i-2, j),(i, j+2)$ and $(i, j-2)$. If one of the neighboring blocks is supported, then the priority index of the block is multiplied by 10 . In the case where the index of a block is equal to 1000 , it must necessarily be integrated into the pillar. This strategy avoids the presence of orphaned blocks (holes in the support) and therefore defects on the surface to support. When a block is supported, its index changes to 0 .

A priority block can take three colors:

- white: the block is not yet supported (but need to);

- rose: the block will be supported by the pillar under construction;

- grey: the block is already supported.

The value of an angle allows one to determine whether the adjacent points require support. If the absolute value of the angle between the $(i+1 ; j)$ and $(i-1, j)$ points is greater than $\alpha$, and the $(i+1, j)$ point is lower than the $(i-1, j)$ point, then this latter does not require support as soon as the $(i+1, j)$ point is supported.

The color of an angle can be:

- white: the absolute value of the angle is less than $45^{\circ}$;

- light gray: the absolute value of the angle exceeds $45^{\circ}$.

Like the decomposition of the part in octree, the construction of the SSM is entirely automatic. The coordinates and the color of octants are contained in a backup file accessible to CAD software. From these data, the software deducts the coordinates of the vertices to support from the SSM.

\section{Case study}

Once the part is discretized, two matrices are obtained. The first is given in Figure 9.

Initially, the SSM matrix contains only the heights of the points of the surface mesh. The priorities are also initialized by the CAD software according to the position of the blocks. The $(2 ; 2)$ block has an initial 
priority of 100 . In fact, this block cannot be physically connected to the support by the $(2 ; 4)$ and $(4 ; 2)$ blocks. This priority prevents the block from becoming an "orphan".

From this matrix, the software can deduce the angles between the vertices of the individual blocks and can start to determine the geometry of the support.

\subsection{Deduction of the support}

From the SSM, seven steps must be performed automatically to generate the support:

1. Calculation of all the angles of the SSM.

2. Coloration in dark gray for the vertices belonging to the blocks which do not require support. This happens where some cells in the SSM correspond to black octants.

3. Indication, in dark gray, for the points which do not require support, based on angles and blocks which do not require support.

4. Location of potential sites for the centers of the pillars. Knowing the length of the edge $c$ of a section of pillar and the width $\mathrm{a}_{\mathrm{nfin}}$ of an octant of the last level $\mathrm{n}_{\text {fin }}$, the number $\mathrm{p}_{\min }$ of blocks necessary for the generation of a pillar is the following:

$$
\left\{\begin{array}{c}
p_{\text {min }}=\left[\frac{c}{a_{n_{f i n}}}\right\rceil \text { if }\left[\frac{c}{a_{n_{f i n}}}\right\rceil \text { odd } \\
p_{\min }=\left\lceil\frac{c}{a_{n_{f i n}}}\right]+1 \text { if }\left[\frac{c}{a_{n_{f i n}}}\right\rceil \text { even }
\end{array}\right.
$$

Only the points located at least at

$$
\frac{p_{\text {min }}-1}{2}+1
$$

points of the matrix board and dark gray points are eligible. These are then colored in dark green in the SSM. 5. Selection of the origin of the pillar to build. By default, it corresponds to the dark green point of smaller height. This allows the support to cover the maximum amount of material of the part to build (Figure 10). 6. Optimization of the volume of the support. By default, the ratio $s$ between the optimized support and a raw vertical block of support covering the same area is set to 0.4 which corresponds to a minimum gain of $60 \%$ of material. This ratio may change depending on the part geometry. The blocks are then deducted iteratively from the $s$ value and colored in red and pink in the SSM. 
7. Coverage of regions with an area smaller than the section of a pillar by slightly degrading the support. It is ensured by the priority index assigned to blocks. These blocks are added to those of the sixth step.

Once a column is generated, it is saved as a matrix in a file. Red and pink cells of SSM are colored respectively in dark gray and gray to allow the construction of the next column. Then the methodology returns to the third step.

\subsection{Representation of the support in a matrix form}

Whenever a column is generated, the following data are included in the backup matrix: localization of the blocks to support, coordinates of the 4 top vertices of each block, height of the lower face of the head, the volume of material of the column, the maximum volume of material.

\section{Case study}

As a result of the previous step, three matrices representing the support are obtained (Figure 11). The last matrix contains no green cell because the surface is completely covered by the support. The pink boxes in the matrix provide an overview of the shape of the support.

\subsection{Support modeling}

The generation of the support by CAD software is done automatically, column after column in separate parts, from backup matrixes and corresponding support matrixes. By convention, the origin of each column is coincident with the point indicated by the cell $(1 ; 1)$ of the array in order to correctly position the support relative to the part. Thus, with a simple coincidence constraint of origins, the support will be directly positioned and oriented relative to the part.

\section{Case study}

Each pillar is generated by following the above explanations for a block edge of $2 \mathrm{~mm}$. All the blocks belonging to the head of the column form a square base cone with angle $\alpha$. The columns are colored in the CAD software to provide a visual aid (Figure 12).

\subsection{Support integration into the part}


Once all pillars are generated, they are incorporated into the part through an assembly. This allows one to visually validate the positioning of the support and apply any modifications.

\section{Case study}

After the assembly of the supports with the part, there is a central symmetry of the support, which suggests that the analysis is relevant to the topology of the part and to the constraints of material, cost and time savings (Figure 13).

\section{Results and analysis}

\subsection{Generalities}

The shape of the support is a relatively accurate discrete representation of the part and the dimensions of the surface to support surface are observed. For an industrial application, the resolution of the support will be less than 250 microns, which allows, during manufacturing the erasure of the defects of the models of columns with respect to the model of the sliced part. Since the support and the part are contained within an assembly file, it is possible to export two files to dissociate the part from the support during the slicing operation.

\subsection{Resulting support}

It is conceivable to produce several iterations of the methodology for different part configurations. The precision as to whether or not a surface has to be in contact with the support would allow one to propose an orientation of a part dependent with the desired amount of support. In order to limit the support, the designer also may slightly degrade the part so as to obtain $\alpha$ respecting surfaces. This assumes that the designer can add material and thus weigh the part.

Regarding the first case study, the flange (Figure 14), the part was produced in ABS on a Makerbot 2X, with an automatically generated support under ReplicatorG. The estimated support volume is $13621 \mathrm{~mm}^{3}$ for a manufacturing time of 33 minutes. The estimated support volume of support with our method is $4148 \mathrm{~mm}^{3}$ for a manufacturing time of 26 minutes. The saving in material is $70 \%$ and in time $21 \%$. We used the same process for the second case study, the brace (Figure 15). The estimated support volume is $16749 \mathrm{~mm}^{3}$ for a 
manufacturing time of 34 minutes and the estimated support volume of support with our method is 7122 $\mathrm{mm}^{3}$ for a manufacturing time of 30 minutes. The saving in material is $57 \%$ and in time $12 \%$.

\section{Conclusions and perspectives}

Existing solutions to integrate support to a part have limitations: the breaking of the digital chain, the simple reduction of the support, the lack of the consideration of accessibility ... The methodology proposed in this paper best fits the needs of designers and manufacturers already using existing solutions. This method is adaptable to any part if the withdrawal of support is taken into account of. The designer can validate the generation of support throughout the CAD without breaking the digital chain. However, this approach still has some limitations.

For the case study, the machine resolution was 250 microns. However, some FDM processes are able to produce parts with an accuracy of 50 microns. It is therefore necessary to improve the analysis part of the methodology by the CAD software to adapt it to the resolution of the machine.

Regarding the case study, a small reduction in manufacturing time was observed. This is explained by the honeycomb structure of the support generated by ReplicatorG while the proposed method uses a "full" structure. It would be interesting to study the feasibility of an optimized support, with a honeycomb structure but with the preservation of the surface in contact with the part. The gain in manufacturing time could also be enhanced by hollowing out the head of the support (Figure 16). However, such a geometry is much more complex to implement.

This method proposes a first optimization of the support for a reasonable calculation time (about 10 min for the case study in a desktop PC). It has the advantage of being virtually automatic. The only tasks to be performed by the designer is to place the part to be studied with respect to the CAD reference and to give the threshold $s$ (ratio between the desired support volume and the maximum volume of support).

We only studied the case of FDM process, because it is one of the rare processes than can manufacture multi material parts. So our work can also be used without any modification for Multi Jet process. For the other processes, with powder bed or liquid polymer, our work could be adapted by replacing the support geometry by lattice structures (Hussein et al, 2013). This would make the cracking of the support easier and reduce the manufacturing time and the cost of the part. 


\section{References}

Ahn, S.-H., Montero, M., Odell, D., Roundy, S. and Wright, P. K. (2002), “Anisotropic material properties of fused deposition modeling ABS", Rapid Prototyping Journal, Vol. 8 No. 4, pp. 248-257.

Allen, S. and Dutta, D. (1995), "Determination and Evaluation of Support Structures in Layered Manufacturing", Journal of Design Manufacturing, Vol. 5, pp. 153-162.

Calignano F. (2014), "Design optimization of supports for overhanging structures in aluminum and titanium alloys by selective laser melting", Materials and Design, Vol. 64, pp. 203-213.

Canellidis, V., Giannatsis, J. and Dedoussis, V. (2009), "Genetic-algorithm-based multi-objective optimization of the build orientation in stereolithography", International Journal of Advanced Manufacturing Technology, Vol. 45 No. 7-8, pp. 714-730.

Dolenc, A. and Makela, I. (1994), "Slicing procedures for layered manufacturing techniques", ComputerAided Design, Vol. 26 No. 2, pp. 119-126.

Durgun, I. and Rukiye, E. (2014), "Experimental investigation of FDM process for improvement of mechanical properties and production cost", Rapid Prototyping Journal, Vol. 20 No. 3, pp. 228 - 235.

Gibson, I., Rosen, D. and Stucker B. (2010), Additive Manufacturing Technologies, Springer, New York, NY.

Hussein, A., Hao, L., Yan, C., Everson, R., Young, P. (2013) “Advanced lattice support structures for metal additive manufacturing”, Journal of Material Processing Technology, Vol. 213, pp. 1019-1026.

Kerbrat, O., Mognol P. and Hascoët J.-Y. (2010) "Manufacturability analysis to combine additive and subtractive processes", Rapid Prototyping Journal, Vol. 16 No. 1, pp. 63-72.

Ma, W., But, W.-C. and He, P. (2004), "NURBS-based adaptive slicing for efficient rapid prototyping", Computer-Aided Design, Vol. 36 No. 13, pp. 1309-1325.

Mognol, P., Lepicart, D. and Perry, N. (2006) "Rapid prototyping: energy and environment in the spotlight", Rapid Prototyping Journal, Vol. 12 No. 1, pp. 26-34.

Nowotny, S., Scharek, S., Beyer, E. and Richter, K.-H. (2007), "Laser beam build-up welding: Precision in repair, surface cladding, and direct 3D metal deposition", Journal of Thermal Spray Technology, Vol. 16 No. 3, pp. $344-348$

Pham, D. T. and Gault, R. S. (1998), “A comparison of rapid prototyping technologies", International Journal of Machine Tools \& Manufacture, Vol. 38 No. 10, pp. 1257-1287.

Ponche, R. (2013), "Méthodologie de conception pour la fabrication additive, application à la projection de poudre", PhD, SPIGA, Ecole Centrale de Nantes.

Singh R. (2013), “ Some investigations for small-sized product fabrication with FDM for plastic components", Rapid Prototyping Journal, Vol. 19 No. 1, pp. 58-63.

Strano, G., Hao, L., Everson, R. M. and Evans, K. E. (2012), "A new approach to the design and optimisation of support structures in additive manufacturing", International Journal of Advanced Manufacturing Technology, Vol. 66 No. 9-12, pp. 1247-1254.

Swaelens, B., Pauwels, J., and Vancraen, W., 1995, “Support Generation for Rapid Prototyping”, in proceedings of the Sixth International Conference on Rapid Prototyping in Dayton, USA, 1995, R. P. Chartoff and A. J. Lightman, Eds. University of Dayton, pp. 115-121. 


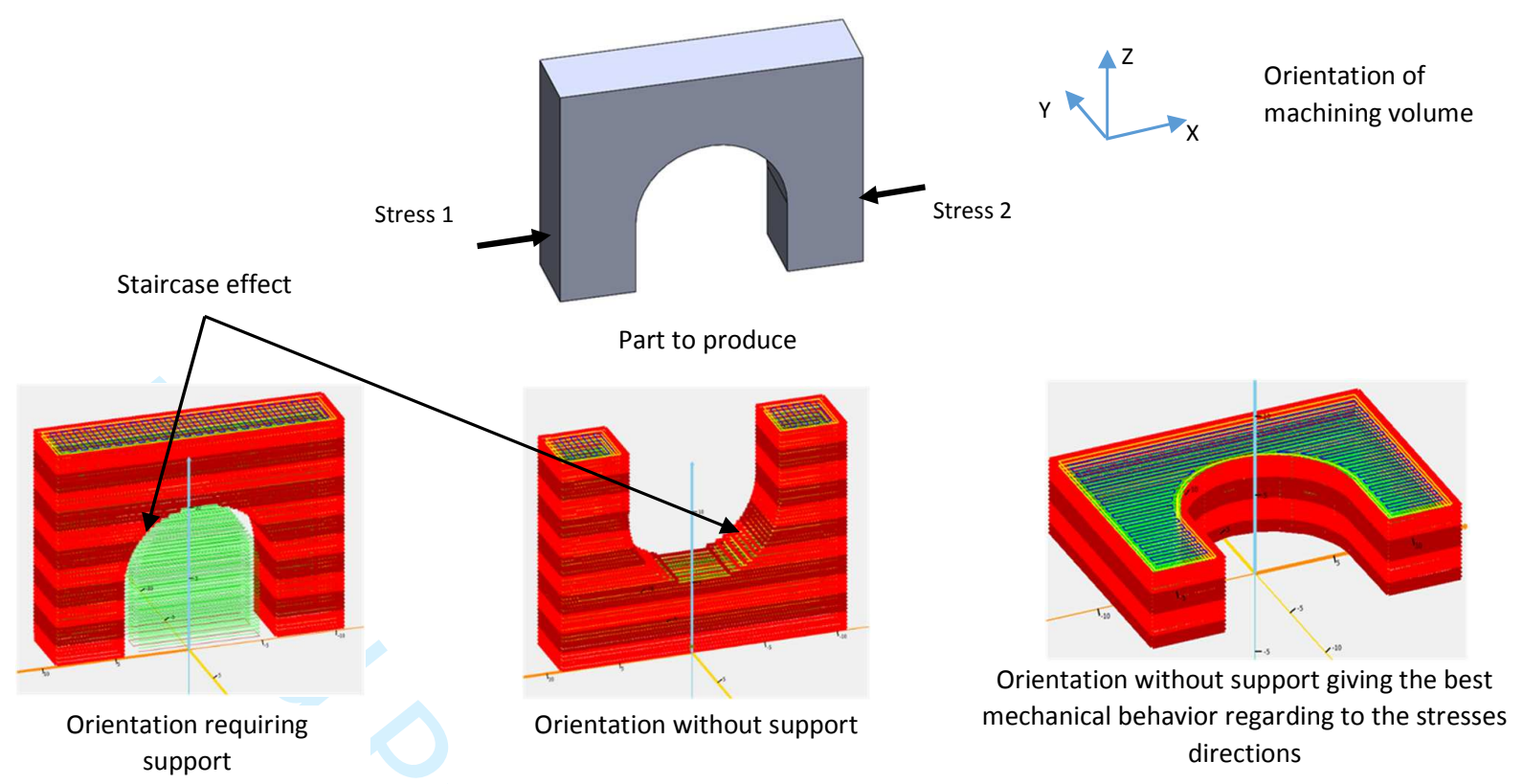

Figure 1 - Support requirement according to part orientation 
Gap between the supports

Structure collapse because of the generated by MeshMixer defficient geometry of the support

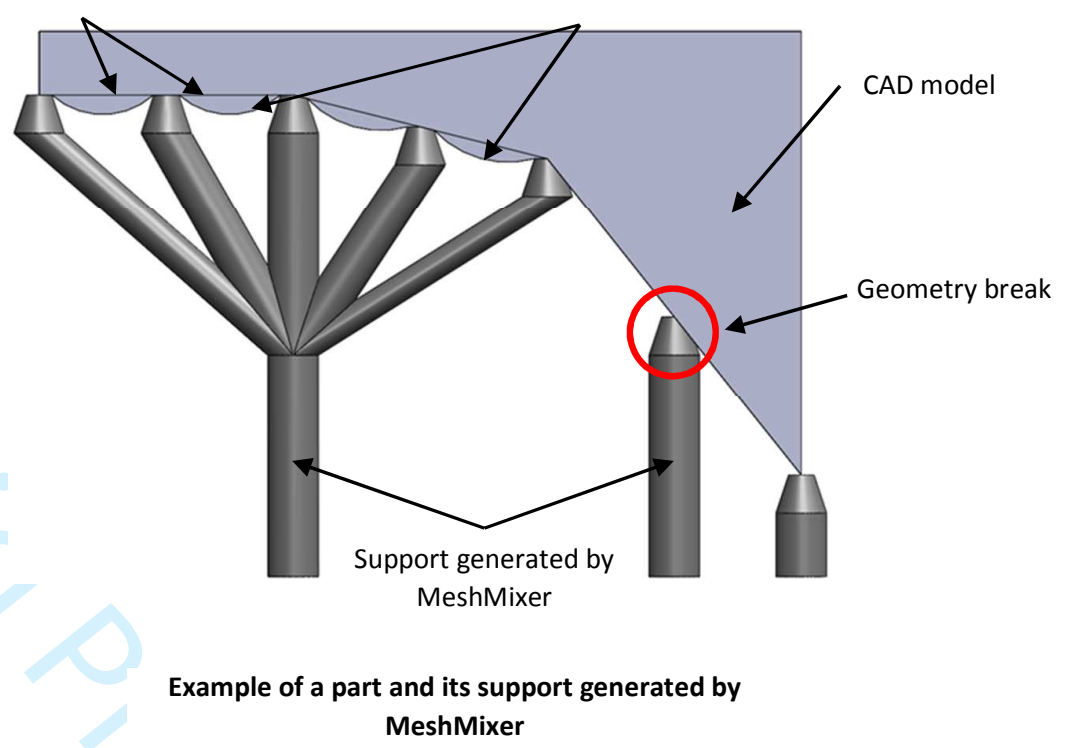

Figure 2 - Collapse of the part geometry because of the deficient integration of the support 
1

2

3

4

5

6

7

8

9

10

11

12

13

14

15

16

17

18

19

20

21

22

23

24

25

26

27

28

29

30

31

32

33

34

35

36

37

38

39

40

41

42

43

44

45

46

47

48

49

50

51

52

53

54

55

56

57

58

59

60

Figure 3 - Generic geometry of support 


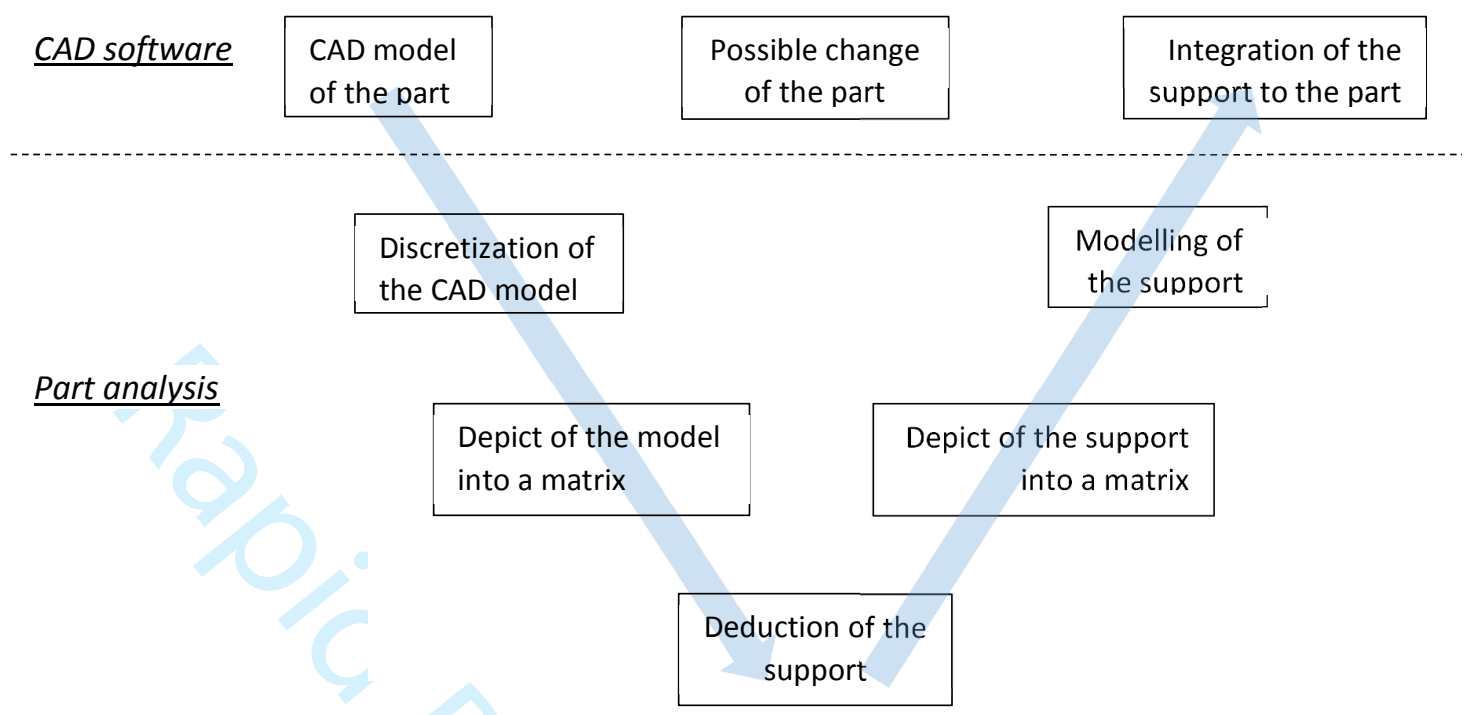

Figure 4-Optimization methodology of the support 

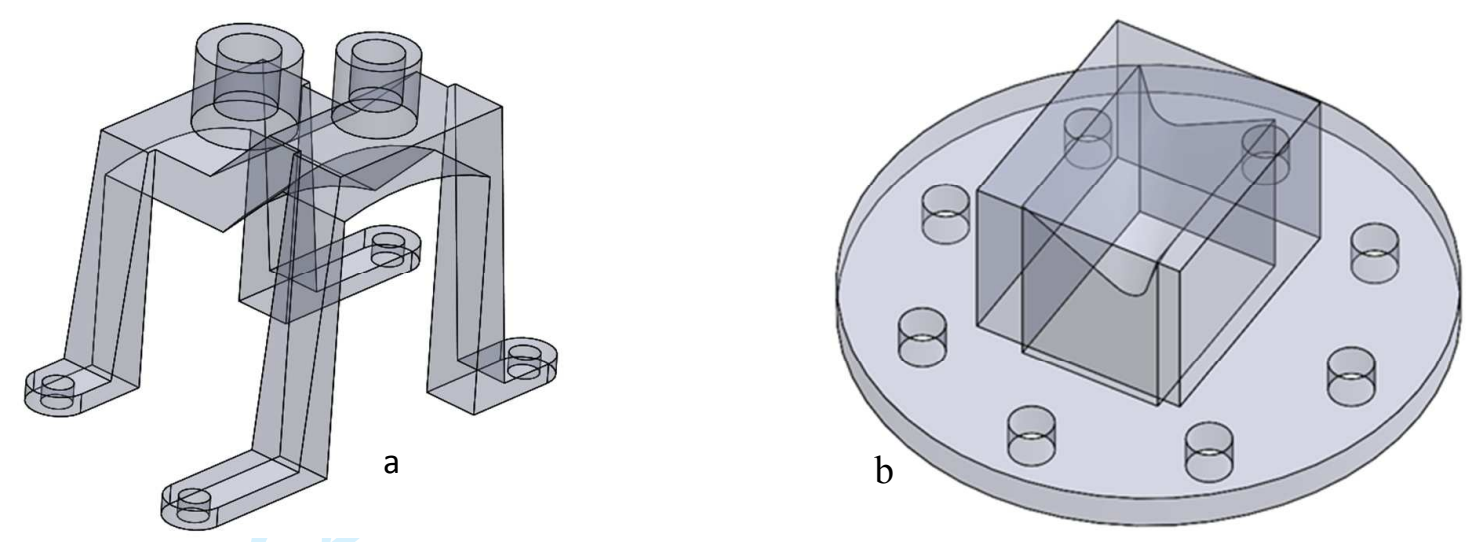

Figure 5 - Case studies for the support optimization ( $a$ - brace, $b$ - flange)

23

24

25

26

27

28

29

30

31

32

33

34

35

36

37

38

39

40

41

42

43

44

45

46

47

48

49

50

51

52

53

54

55

56

57

58

59

60 


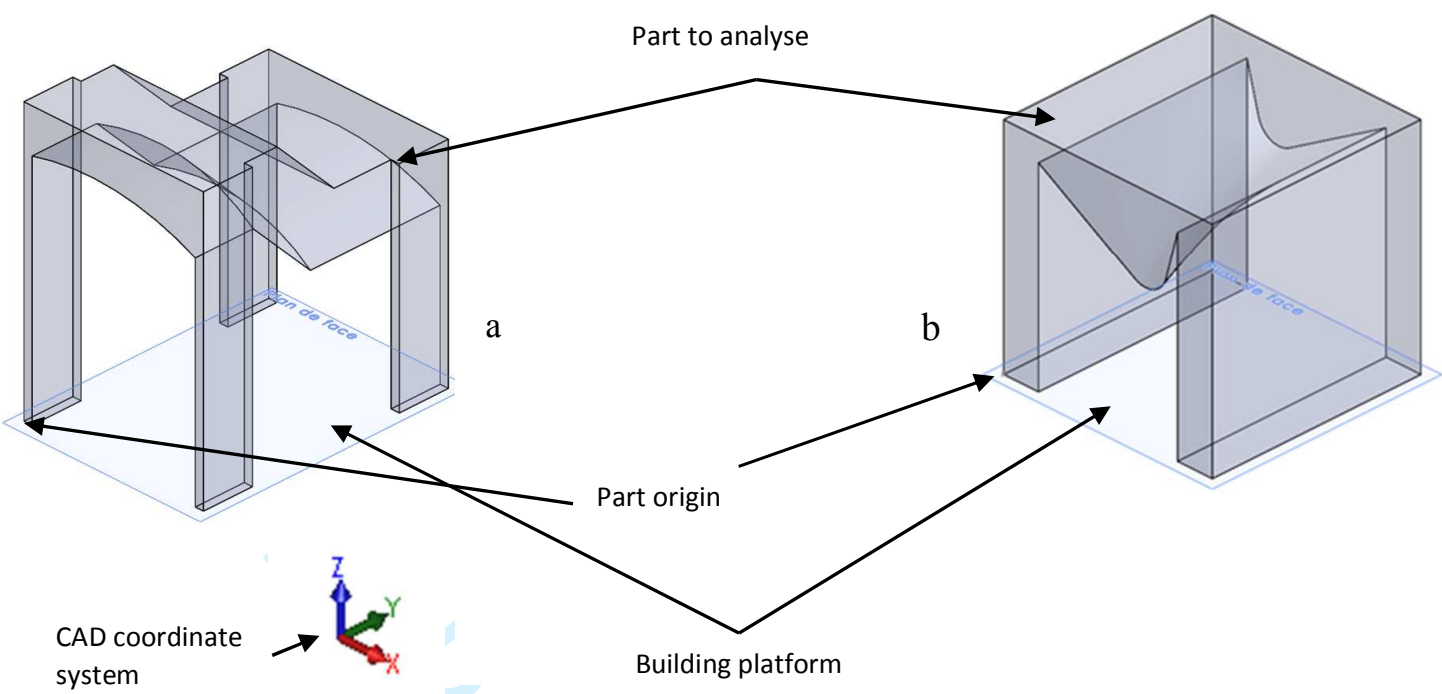

Figure 6 - Parts oriented in CAD coordinate system (a - brace, b - flange) 
Axis of increasing Z

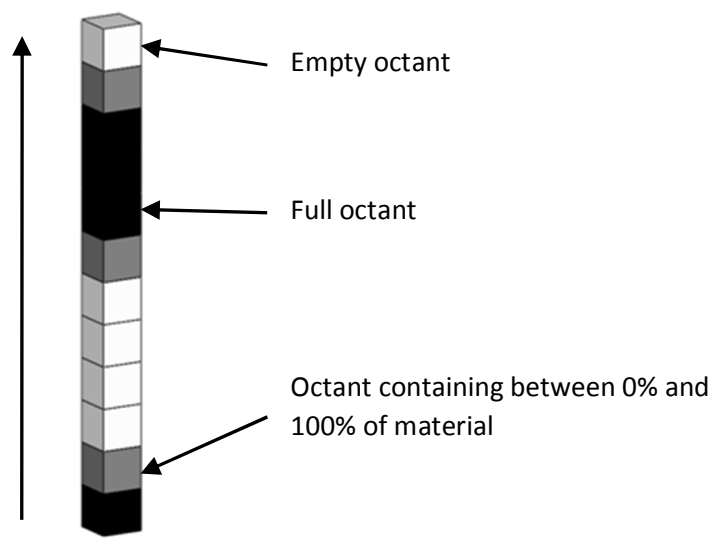

Figure 7 - Graphic representation of an octant stack 


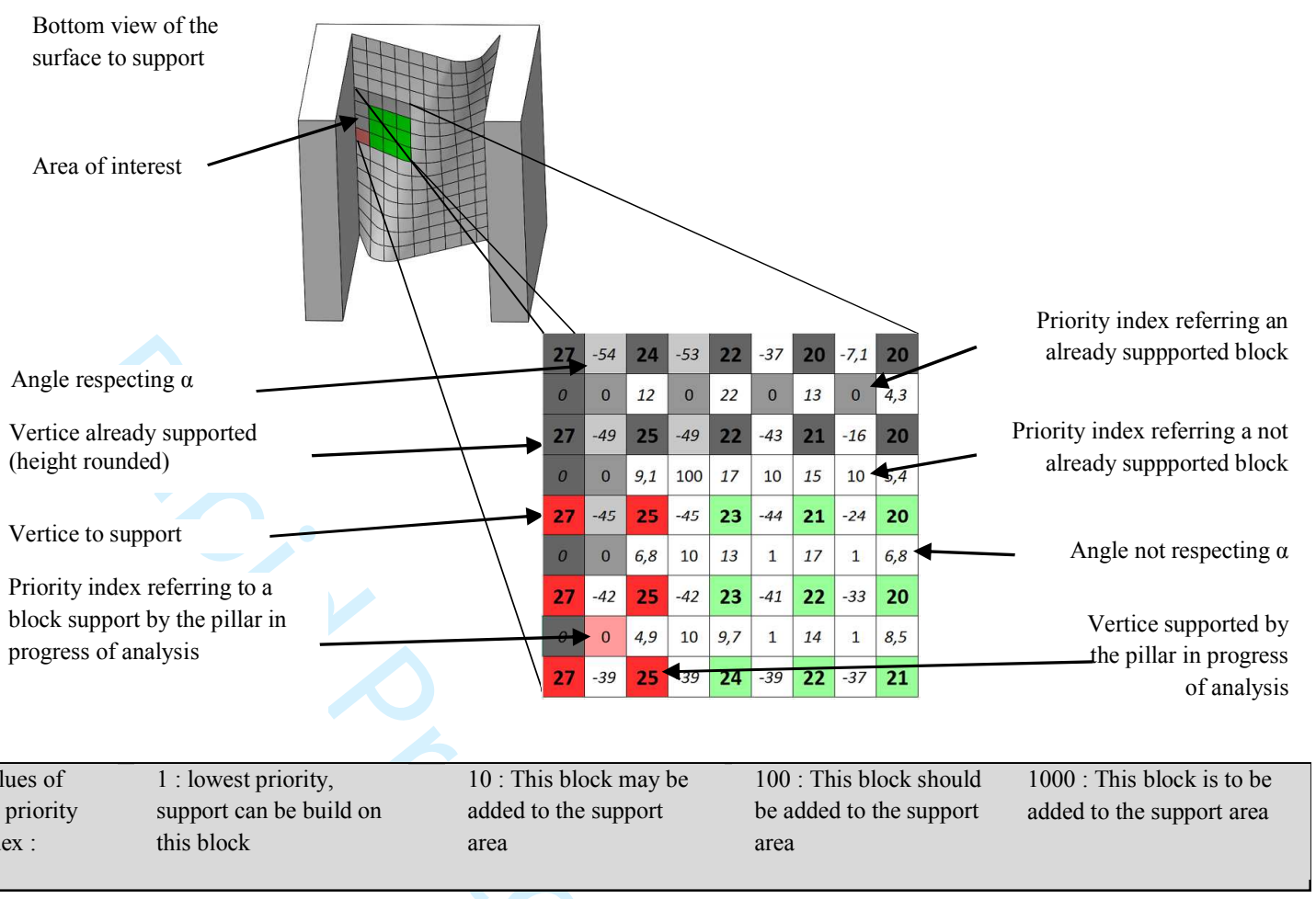

Figure 8 - Example of SSM 


\begin{tabular}{|c|c|c|c|c|c|c|c|c|c|c|c|c|c|c|c|c|c|c|c|c|}
\hline 27 & & 20 & & 18,6 & & 18,9 & & 20,1 & & 21,2 & & 22,4 & & 23,5 & & 24,7 & & 25,9 & & 27 \\
\hline & 100 & & 10 & & 10 & & 10 & & 10 & & 10 & & 10 & & 10 & & 10 & & 100 & \\
\hline \multirow[t]{2}{*}{27} & & 21,6 & & 19,2 & & 19 & & 20 & & 21,1 & & 22,3 & & 23,5 & & 24,7 & & 25,8 & & 27 \\
\hline & 10 & & 1 & & 1 & & 1 & & 1 & & 1 & & 1 & & 1 & & 1 & & 10 & \\
\hline \multirow[t]{2}{*}{27} & & 22,8 & & 19,9 & & 19,3 & & 19,8 & & 21 & & 22,2 & & 23,4 & & 24,6 & & 25,8 & & 27 \\
\hline & 10 & & 1 & & 1 & & 1 & & 1 & & 1 & & 1 & & 1 & & 1 & & 10 & \\
\hline \multirow[t]{2}{*}{27} & & 23,7 & & 20,7 & & 19,7 & & 19,7 & & 20,8 & & 22 & & 23,3 & & 24,5 & & 25,8 & & 27 \\
\hline & 10 & & 1 & & 1 & & 1 & & 1 & & 1 & & 1 & & 1 & & 1 & & 10 & \\
\hline \multirow[t]{2}{*}{27} & & 24,2 & & 21,6 & & 20,1 & & 19,8 & & 20,5 & & 21,8 & & 23 & & 24,4 & & 25,7 & & 27 \\
\hline & 10 & & 1 & & 1 & & 1 & & 1 & & 1 & & 1 & & 1 & & 1 & & 10 & \\
\hline \multirow[t]{2}{*}{27} & & 24,7 & & 22,4 & & 20,5 & & 20 & & 20,3 & & 21,5 & & 22,9 & & 24,3 & & 25,6 & & 27 \\
\hline & 10 & & 1 & & 1 & & 1 & & 1 & & 1 & & 1 & & 1 & & 1 & & 10 & \\
\hline \multirow[t]{2}{*}{27} & & 25 & & 23 & & 21,1 & & 20,2 & & 20,2 & & 21,1 & & 22,6 & & 24,1 & & 25,5 & & 27 \\
\hline & 10 & & 1 & & 1 & & 1 & & 1 & & 1 & & 1 & & 1 & & 1 & & 10 & \\
\hline \multirow[t]{2}{*}{27} & & 25,2 & & 23,5 & & 21,7 & & 20,4 & & 20,1 & & 20,7 & & 22,2 & & 23,8 & & 25,4 & & 27 \\
\hline & 10 & & 1 & & 1 & & 1 & & 1 & & 1 & & 1 & & 1 & & 1 & & 10 & \\
\hline \multirow[t]{2}{*}{27} & & 25,4 & & 23,8 & & 22,2 & & 20,7 & & 20,1 & & 20,4 & & 21,7 & & 23,5 & & 25,2 & & 27 \\
\hline & 10 & & 1 & & 1 & & 1 & & 1 & & 1 & & 1 & & 1 & & 1 & & 10 & \\
\hline \multirow[t]{2}{*}{27} & & 25,5 & & 24,1 & & 22,6 & & 21,1 & & 20,2 & & 20,2 & & 21,1 & & 23 & & 25 & & 27 \\
\hline & 10 & & 1 & & 1 & & 1 & & 1 & & 1 & & 1 & & 1 & & 1 & & 10 & \\
\hline \multirow[t]{2}{*}{27} & & 25,6 & & 24,3 & & 22,9 & & 21,5 & & 20,3 & & 20 & & 20,5 & & 22,4 & & 24,7 & & 27 \\
\hline & 10 & & 1 & & 1 & & 1 & & 1 & & 1 & & 1 & & 1 & & 1 & & 10 & \\
\hline \multirow[t]{2}{*}{27} & & 25,7 & & 24,4 & & 23,1 & & 21,8 & & 20,5 & & 19,8 & & 20,1 & & 21,6 & & 24,2 & & 27 \\
\hline & 10 & & 1 & & 1 & & 1 & & 1 & & 1 & & 1 & & 1 & & 1 & & 10 & \\
\hline \multirow[t]{2}{*}{27} & & 25,8 & & 24,5 & & 23,3 & & 22 & & 20,8 & & 19,7 & & 19,9 & & 20,7 & & 23,7 & & 27 \\
\hline & 10 & & 1 & & 1 & & 1 & & 1 & & 1 & & 1 & & 1 & & 1 & & 10 & \\
\hline \multirow[t]{2}{*}{27} & & 25,8 & & 24,6 & & 23,4 & & 22,2 & & 21 & & 19,8 & & 19,2 & & 19,9 & & 22,8 & & 27 \\
\hline & 10 & & 1 & & 1 & & 1 & & 1 & & 1 & & 1 & & 1 & & 1 & & 10 & \\
\hline \multirow[t]{2}{*}{27} & & 25,8 & & 24,7 & & 23,5 & & 22,3 & & 21,1 & & 20 & & 19 & & 19,2 & & 21,6 & & 27 \\
\hline & 100 & & 10 & & 10 & & 10 & & 10 & & 10 & & 10 & & 10 & & 10 & & 100 & \\
\hline 27 & & 25,9 & & 24,7 & & 23,5 & & 22,4 & & 21,2 & & 20,1 & & 18,9 & & 18,6 & & 20 & & 27 \\
\hline
\end{tabular}

Figure 9 - Pristine SSM of the study part 


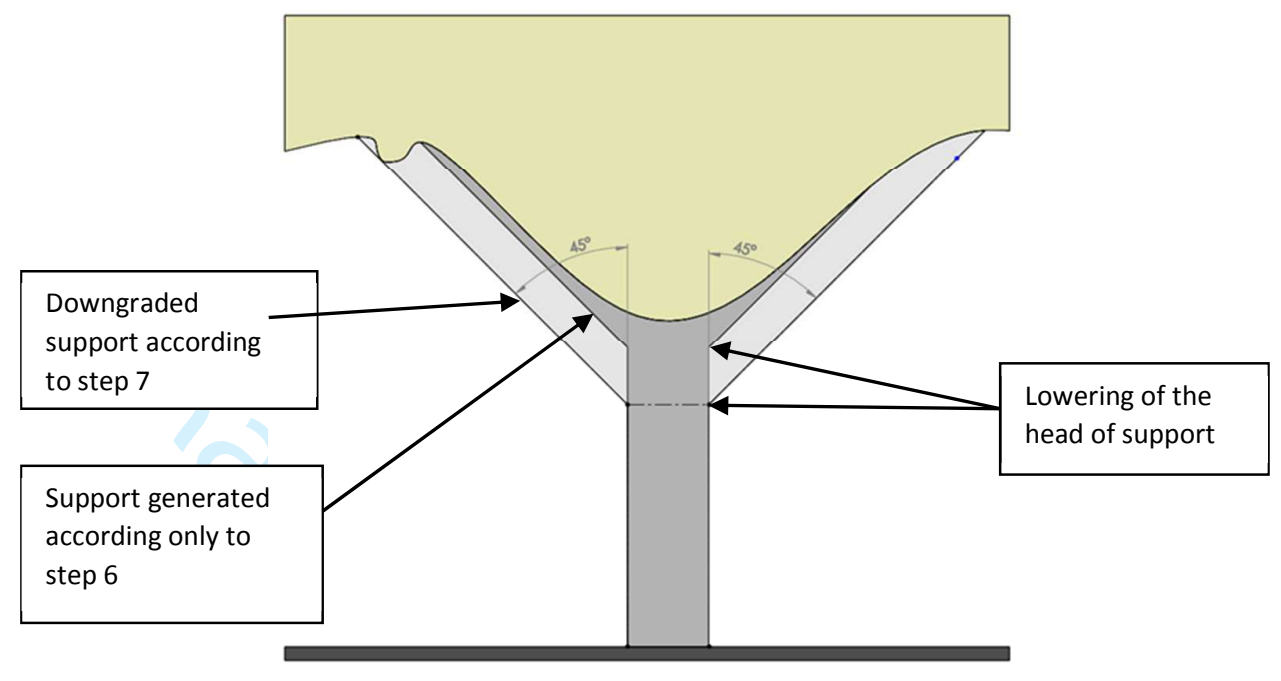

Figure 10 - Downgrade of a pillar to adapt the support to the part geometry 

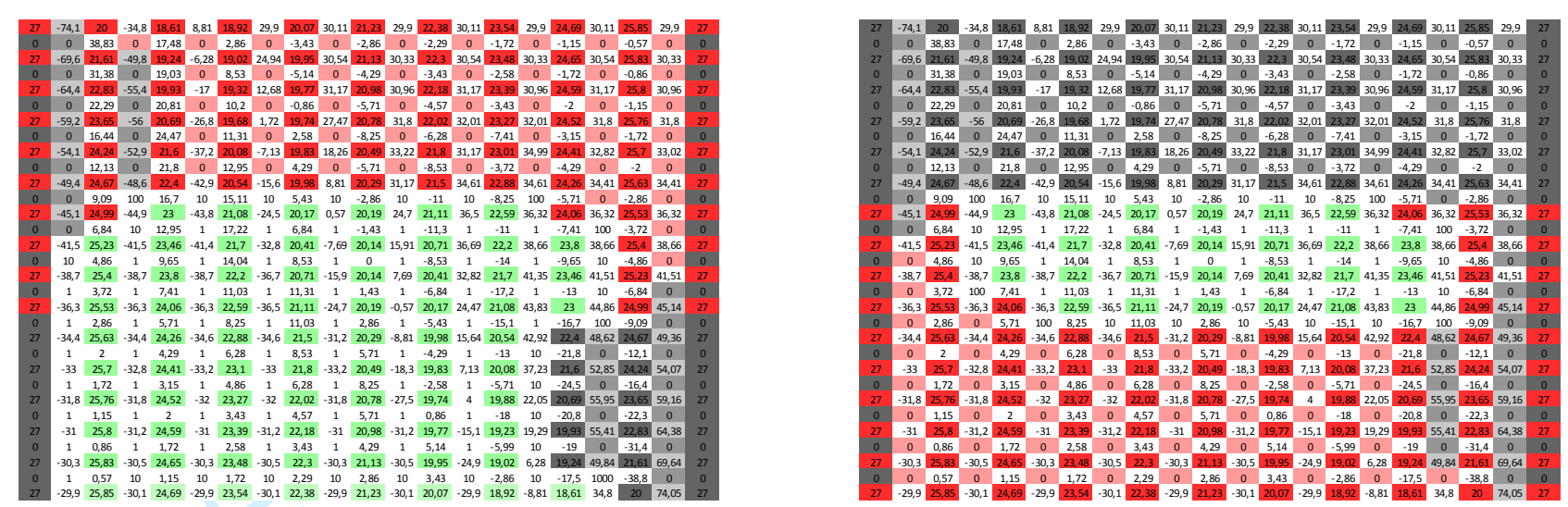

Deduction of the first pillar

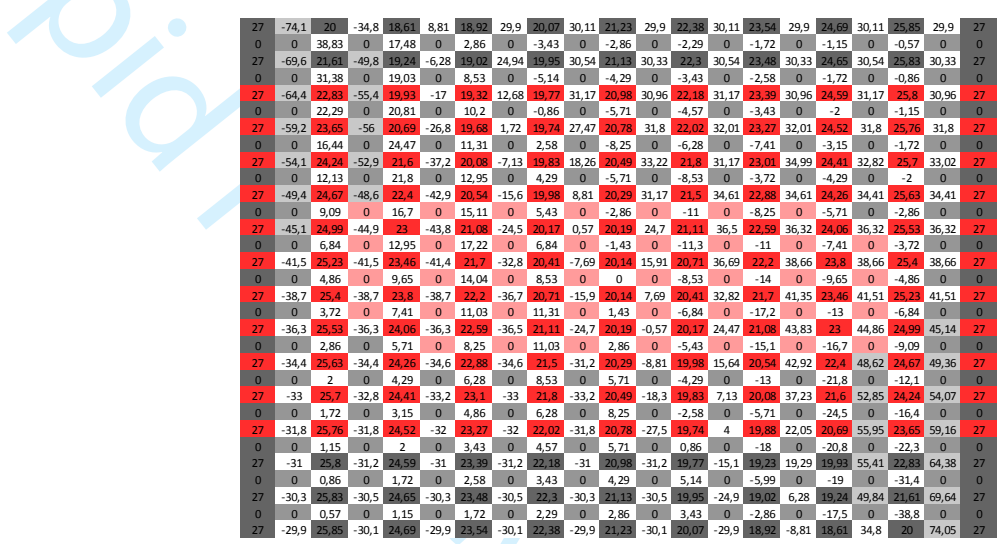

Deduction of the last pillar

Figure 11 - Successive steps of support deduction

Deduction of the second pillar 

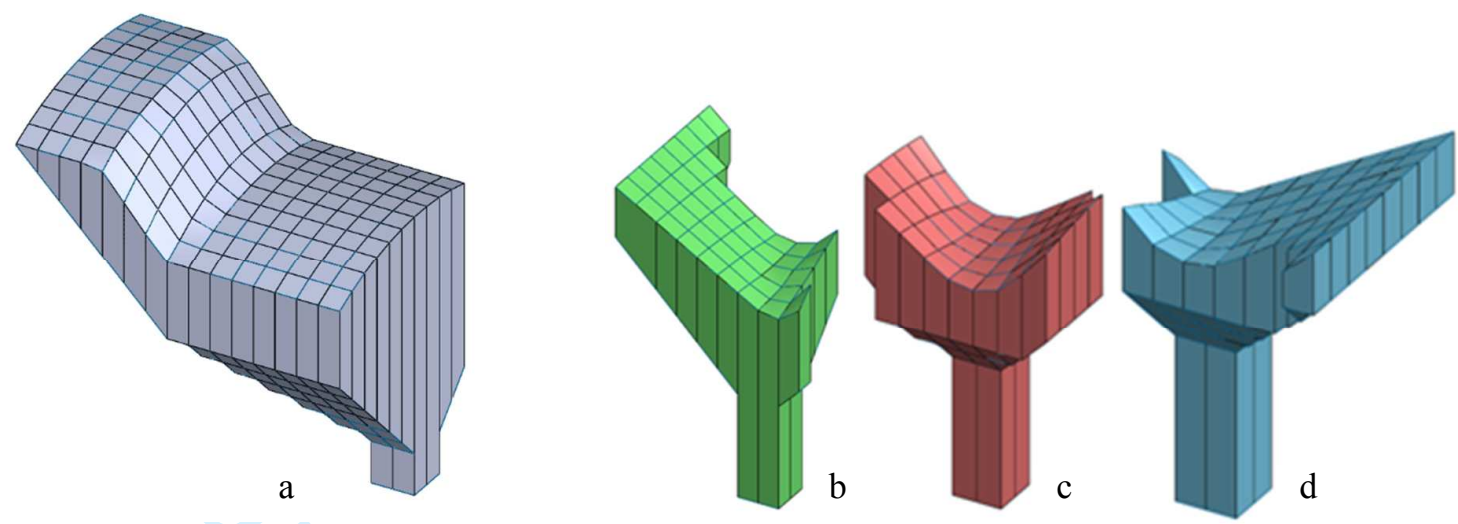

Figure 12 - CAD models of supports generated from the SSMs (a - brace, b, $c$ and $d$ - flange) 

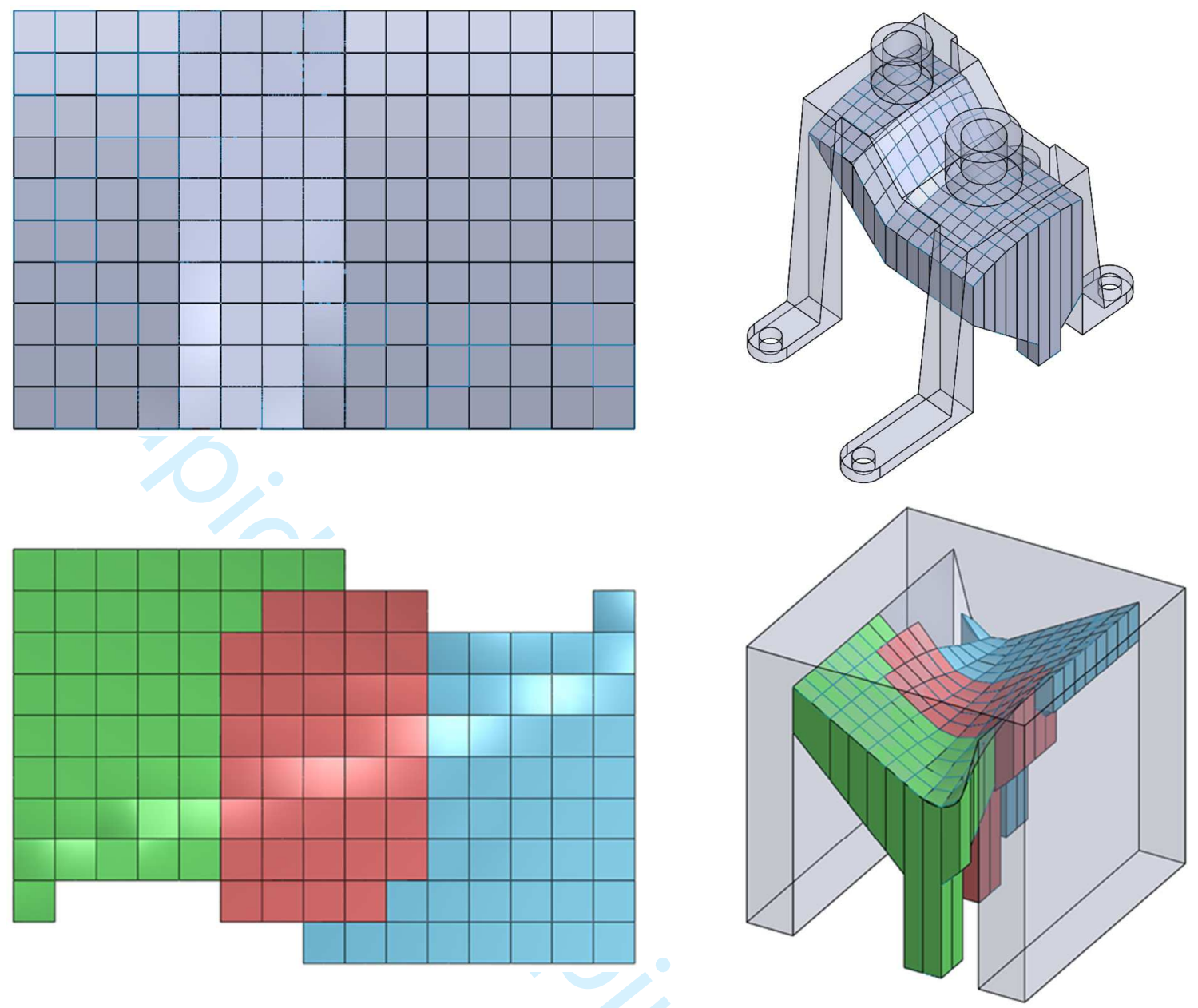

Figure 13 - Integration of the support in the DAC model of the part (up - brace, down - flange) 


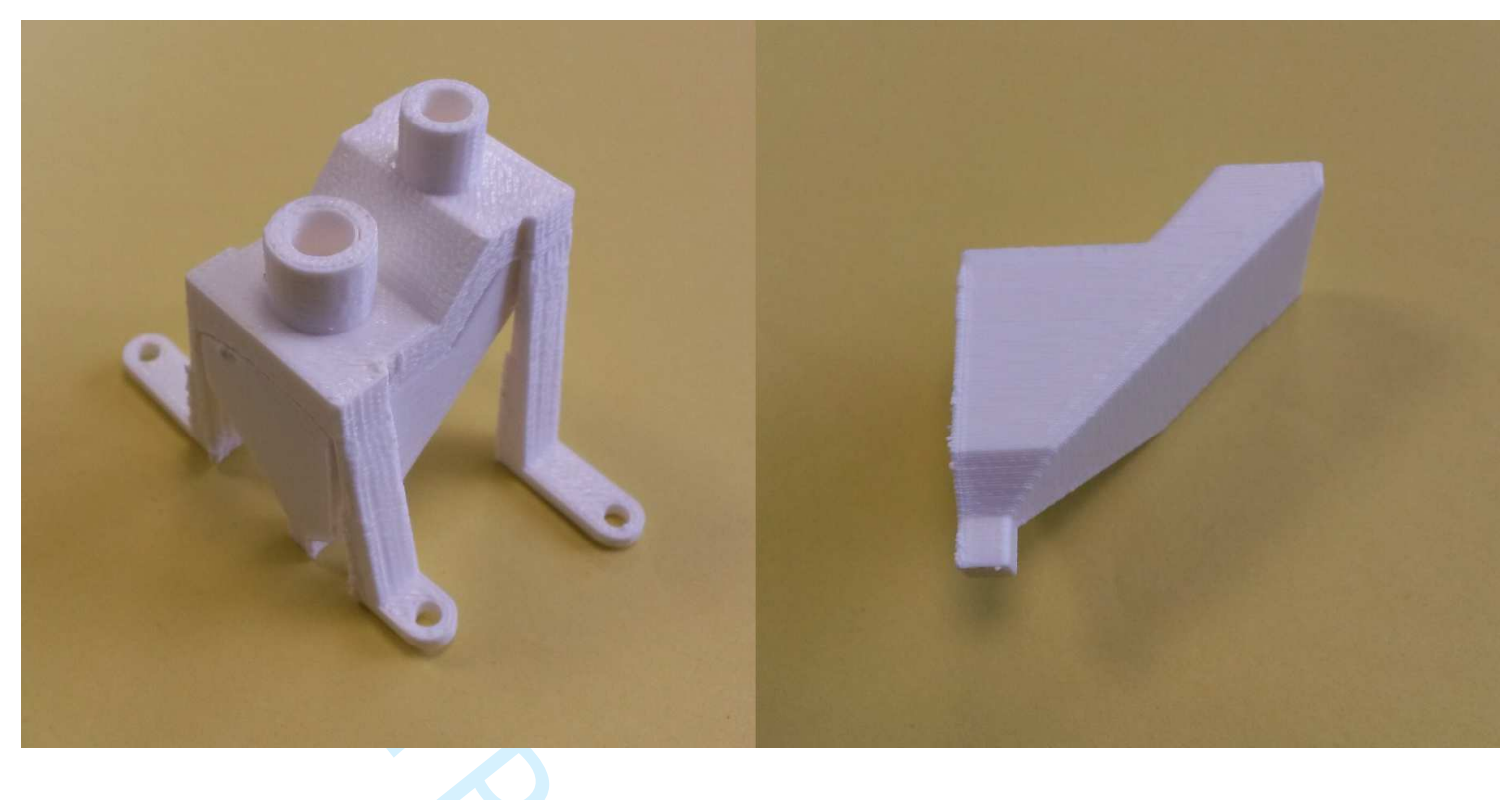

Figure 14-Built brace (left: part + support - right: support) 


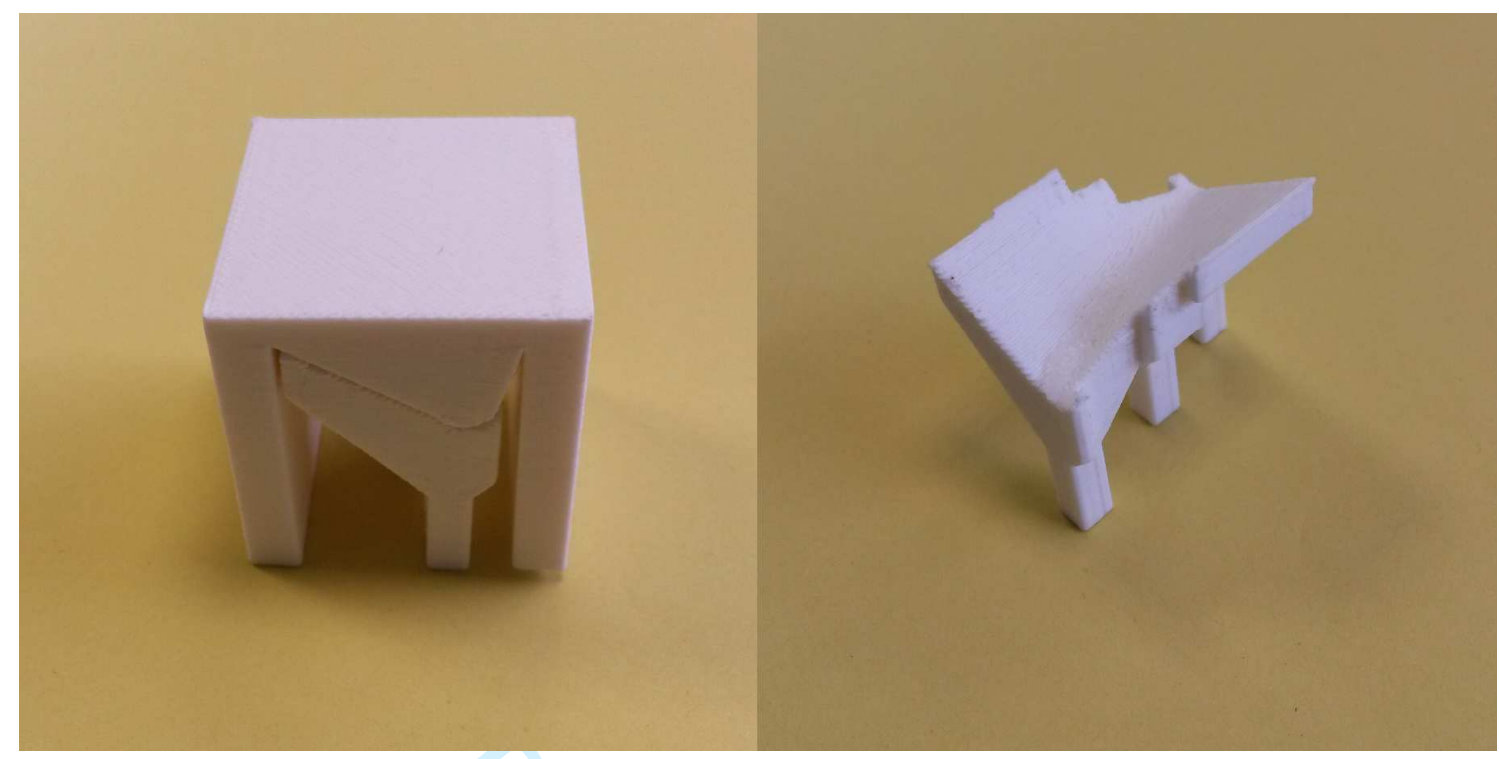

Figure 15 - Built flange (left: part + support - right: support) 
